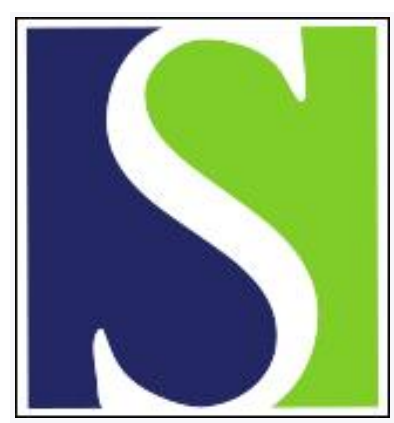

Scand J Work Environ Health 1984;10(6):341-346

https://doi.org/10.5271/sjweh.2309

Issue date: Dec 1984

Work-related diseases. A new program of the World Health Organization.

by el Batawi MA

This article in PubMed: www.ncbi.nlm.nih.gov/pubmed/6535237

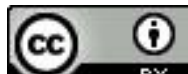




\title{
Work-related diseases
}

\section{A new program of the World Health Organization}

\author{
by Mostafa A El Batawi, MD, ScD 1
}

\begin{abstract}
El BATAWI MA. Work-related diseases: A new program of the World Health Organization. Scand $J$ Work Environ Health 10 (1984) 341-346. "Work-related diseases" are multifactorial diseases in which the work environment plays a partial role in causation. They include chronic noncommunicable disease affecting working populations. There is evidence that such diseases as musculoskeletal disorders, hypertension, chronic bronchitis, and several psychosomatic disturbances affecting workers can be attributed to a variety of risk factors, including those in the workplace. Examples of investigations and the occurrence of various work-related diseases are cited from several countries. Occupational health is evolving to deal with multifactorial health problems from combined exposure to occupational and other environmental factors, life-style, and individual susceptibility. More attention should be given to psychosocial factors and ergonomics in the workplace, workers' participation and life-style, multifactorial occupational epidemiology, and new approaches to legislation. A list of research areas is given to cover the present gaps in knowledge. The World Health Organization has started a program of work in this field to identify the magnitude of these diseases in various parts of the world, to stimulate epidemiologic research, and to develop guidelines for control measures.
\end{abstract}

Key terms: combined effects, ergonomics, job analysis, life-style, multifactorial diseases, new dimensions of occupational health, psychosocial factors at work, WHO, workers' participation, work-relatedness to disease.

As a well-adjusted and profitable activity of man, work can be a factor in health promotion, but, when it produces excess risks, it may affect health in one or more of the following ways: (i) it may cause occupational diseases from specific physical, chemical, and biological exposure; (ii) it may lead to aggravation of any existing diseases of nonoccupational origin; and (iii) it may be a factor in a number of diseases with multiple etiology.

This paper is an introductory account on the last type of work-relatedness to disease.

In 1976 a review of the occupational health program of the World Health Organization (WHO) was presented to the World Health Assembly; it suggested new dimensions of work-relatedness to health and disease (18). Not only that "occupational diseases" are the inevitable result of workers' exposure to specific occupational hazards, but that there are also several other health problems of varying magnitude that have to be dealt with in the development of occupational health programs. Work-relatedness to multifactorial diseases comes from the fact that human life at home, at work, and during leisure time is a continuity that does not recognize the boundaries that separate the work environment from the general environment. It also stems from the fact that heredi-

\footnotetext{
1 World Health Organization, Geneva, Switzerland.

Reprint requests to: Prof MA El Batawi, World Health Organization, CH-1211 Geneva 27, Switzerland.
}

tary and life-style factors influencing human health do not stop at the gates of workplaces. The term "work-related diseases" was therefore given to a variety of disorders that were probably more prevalent among working people than specific occupational diseases. Examples of hypertension, arthritis and musculoskeletal disorders, gastroduodenal ulcer, chronic nonspecific obstructive respiratory diseases, and psychological and behavioral disorders were later cited, together with epidemiologic evidence demonstrating the role played by the work environment in their causation (5). It became readily obvious that occupational health was undergoing an evolutionary trend that was similar to the one followed earlier by public health. In the past public health was predominantly concerned with infectious diseases in which various pathological microorganisms were the single direct cause of illness. In the 1930s, the "diseases of civilization," generally including cardiovascular diseases, obstructive lung diseases, cancer, arthritis, and other multifactorial chronic diseases, were becoming more frequent in the industrialized world, and with the improvement of sanitation communicable diseases were on the decline.

In occupational health a large body of information is now available on the specific principal causative agents of occupational diseases and the corresponding effects on man at different levels of exposure. Such diseases as lead poisoning, silicosis, noiseinduced hearing loss can readily be identified to- 
gether with causative factors. They can effectively be controlled at the source of risk by protective measures in the work environment. On the other hand, in "work-related diseases," the role of work in causation is less identifiable than in the case of occupational diseases, and the role of other risk factors in the general environment and in human behavior and other susceptibilities have to be evaluated. Workrelated diseases would require a multidisciplinary health approach for their prevention, with occupational health services as one of the disciplines.

Work-related diseases include, on one end of the spectrum, occupational diseases in which the causal relationship to specific quantifiable occupational hazards is established. Other work-related diseases come next and vary from the very limited causal relationship to work to the more substantial and better documented relationship. There are many gaps in the knowledge about the degree to which work plays its role as one of the risk factors involved. Hopefully, through careful epidemiologic observation, it may be possible in the future to quantify, even in an approximate manner, the degree of causal work-relatedness of various diseases.

In 1982 and 1983 two WHO groups of experts met on this subject and made the following definition (17): “" work-related diseases' may be an appropriate term to describe disorders other than and in addition to recognized occupational diseases that occur among working people when the work environment and performance contribute significantly, but in varying magnitude to disease causation." Workrelated diseases, as distinguished from specific occupational diseases, usually affect the general population, including workers; they are caused by, or are associated with, risk factors which may at times be encountered in the work environment.

\section{Examples of some work-related diseases}

The National Institute for Occupational Safety and Health (NIOSH) of the United States reported 10 "leading work-related diseases and injuries" in the United States in 1983 (12). Some of these "leading 10 " are clear-cut occupational diseases, eg, asbestosis, silicosis, occupational dermatosis, and noiseinduced hearing loss. Others, such as cardiovascular diseases, may be less directly related to health hazards in the work environment. However, two of the main risk factors of ischemic heart disease, hypertension and smoking, have been described as related to occupational psychosocial stress $(1,14)$; and this finding may present indirect evidence of work-relatedness to ischemic heart disease. In recent observations reported in Sweden $(9,15)$, work overload was also suspected in respect to an increased occurrence of myocardial infarction.

Some of the evidence demonstrating the role played by work and work conditions in the causation of multifactorial health problems of workers has been reviewed by the WHO committee on the subject in 1983 (17). There is evidence that behavioral disorders and psychosomatic disturbances affecting certain groups of workers may be the result of combined exposure to adverse psychosocial factors both at work and in the general living environment, together with workers' susceptibility. Some highly suggestive evidence also exists on the work-relatedness of hypertension with overload on the job (1).

The low-back pain syndrome has more strongly been documented as a work-related health problem. It is a multifactorial syndrome that may result from inflammatory, degenerative, neoplastic, traumatic, and gynecologic disorders and is often associated with congenital back defects, weak muscles, and rheumatic predisposition. The most common lowback pain is, however, a nonspecific symptom associated with posture and improper lifting of objects at work or outside work. Low-back pain prevails highly in working populations, but, in view of the fact that it is a multifactorial syndrome associated with nonspecific conditions that are not essentially occupational, it is not always easy to establish its occupational specificity, for example, in workmen's compensation claims.

Chronic obstructive pulmonary disease is also multifactorial. It affects susceptible smokers, and people exposed to general air pollution, but it becomes more frequent when the same people are also exposed to pollutants in the work environment, which, on its own, may not actually cause as much pulmonary disorder nor any of the specific occupational pulmonary diseases (8).

\section{Occurrence of work-related diseases in various parts of the world}

There has always been a shortage of information on the occurrence of even the occupational diseases prescribed in the statutory schedules of notifiable diseases in countries where affected workers are entitled to compensation. Compared with work-related diseases, occupational diseases should not present much problem in their recognition in view of the feasibility of understanding cause-effect relationship and the relative ease in identifying the causative occupational hazards by simple means. It is expected that much less information on work-related diseases would be available because of the more complex causation and the difficulty in identifying the particular factor(s) in the work environment that might have been involved.

Occupational disease reporting has been limited in many countries by the fact that such reporting is usually followed by legal action, including the enforcement of preventive measures that may be seen as costly to many of the employers who hire the medical practitioners. This particular factor is expected to 
play a more important role in the resistance against the work-relatedness of general diseases that are not included in prescribed lists.

However, there are several field studies and reports that reflect the interest in work-related diseases in various parts of the world, particularly in the United States, France, Finland, Sweden, the United Kingdom, Italy, the Republic of Korea, Egypt, Sudan, Poland, and others. In the United States the 10 leading groups of diseases referred to earlier are at present subject to careful examination as to their occurrence and control. Studies of alcoholism and drug abuse in industry were also performed in the United States with evidence of relatedness to stress at work $(7,16)$.

Studies have been conducted on hypertension and ischemic heart disease in various industries. In France the mortality of men in the age group 44 to 65 years from cerebrovascular diseases was higher among farm workers $(138 / 100000)$ and farmers $(120 / 100000)$, much lower among other groups of workers $(79 / 100000)$, and the lowest among professional categories $(57 / 100$ 000) (3). In the Republic of Korea a survey was conducted on 5000 factory workers in 1981; it revealed that the prevalence of hypertension ranges from 15 to $21 \%$, depending on age, but it is generally higher than the general Korean average of $8 \%$. In the same country workers with predominantly mental tasks suffer more from hypertension than workers with physical tasks (Cho, personal communication). In the United Kingdom marked differences in mortality from ischemic heart disease were observed among British civil servants (10). Thus the age-adjusted risk of the lowest grade of civil servants to die from ischemic heart disease was four times higher than that of the highest administrative grade. In Finland observation of cardiovascular disease mortality in various occupations showed that mortality was higher among certain workers in manufacturing, mining, and forestry and among unskilled construction workers than among technical workers, administrators, construction carpenters, and fishermen (13).

In Poland a five-year follow-up study of an industrial population showed that the prevalence and development of chest symptoms in men were related mainly to their smoking habit and to a less degree to age, but "the five-year incidence study showed that particular occupational factors do indeed have a real effect [p 210]" (8).

In Sweden a general population study showed that sulfite pulp factory workers who smoke seemed to run a high risk of contracting chronic bronchitis (11).

In Egypt the prevalence of chronic bronchitis among smokers exposed to irritant exhausts of motor vehicles was $8.7 \%$ as compared to $5.6 \%$ among smokers who were not exposed to these effluents (6). In the same country a cross-sectional study of some 92000 workers employed in 152 industrial plants rep- resenting 17 major types of industry suggested inter alia that digestive disorders were significantly higher among workers exposed to overload on the job, heat stress, and meal irregularity. The study also demonstrated that chronic bronchitis was higher when smoking was associated with exposure to respiratory irritants in the workplaces (4).

In Italy a sociostatistical study of gastric and duodenal ulcer was made among a population of more than 200000 workers for one year. There appeared to be a clear link between "industrial" work and peptic ulcer. It was hypothesized that the types of work involving heat exposure, exposure to odors and other vapors, and, in particular, to psychosocial stress at work, together with irregular eating habits and other aspects of living, were the main risk factors (2).

In the Sudan schistosomiasis was described as a work-related disease on the grounds that it affects the population at large and particularly agricultural workers exposed to infestation at work. If this disease is considered "work-related" on these grounds, it is one of the highly prevailing health problems in various parts of the world.

The afcrementioned studies, in addition to demonstrating interest in the epidemiologic aspects of the work-relatedness of several health problems in various parts of the world, also point to the need for much more research in this field. The cited studies suffer, in general terms, from the following three problems:

1. The demonstrable relationships lack specific analysis of possible risk factors in the work environment. This is particularly true of mortality studies in relation to social status and type of employment.

2. There is a lack of attention to many environmental and human variables that could have played a role in the occurrence of various diseases.

3. There is a complete absence of any attempt to quantify, even in general terms, the degree to which work played a role in the occurrence of these diseases.

\section{Implications for occupational health}

Occupational health is an established discipline with a broad scope that is not only limited to the prevention and control of specific occupational diseases. Workers' health is indivisible, and their health problems are the outcome of exposures outside and inside workplaces, in addition to factors determined by the workers' own life-style and susceptibilities. It is therefore inevitable for occupational health to deal with work-related multifactorial diseases and share, with other health disciplines, the responsibility for their prevention and control. 
Much of present occupational health practice is as limited in scope as it was in the old times. At the government level in many countries the medicolegal aspects prevail, legislation and inspection of the workplaces remaining as the main tools to put the classical hazards, such as toxic substances, dusts, and noise, under control. At the level of the workplace, at its best, it is a coordinated medical and occupational hygiene effort aiming to detect and control specific health problems. At the scientific level, it involves research in specific areas, including the study of the mechanism of action of toxic substances, development of new methods and techniques for environmental and biological monitoring, etc. While all of these practices must continue and improve, there are additional requirements that have to be fulfilled to deal with workers' total health in a complete and more positive manner, including the prevention and control of work-related diseases.

\section{New dimensions for occupational health in the workplace}

It has generally been noted that there are certain occupational risk factors that play a role in the causation of work-related diseases. These are relatively new and probably have not been given much attention. For example, adverse psychosocial factors at work have been blamed for some of the psychosomatic and behavioral disorders, for an increased rate of alcoholism and smoking, for an increased rate of hypertension, and, possibly also, for the problem of gastroduodenal ulcer. The limited use of ergonomics and errors in performing physical tasks were blamed for many of the diseases of the musculoskeletal system. The combined effects of low concentration levels of potentially toxic elements, odors, and monotony are often associated with vague manifestations of general fatigue, headache, anxiety, and a lowering of body resistence. There is also the possibility of a role, yet unexplained, of immune response. Until such a time when the unexplained areas become clearer, it should be necessary to incorporate some new measures into the classical occupational health practice in workplaces. Four examples follow.

1. A program is needed for monitoring psychosocial factors in the work environment and the resulting health effects. Just as there are, at present, ways and means for evaluating physical and chemical exposures in the work environment and for biological monitoring, occupational health sciences will have to develop methods for identifying, monitoring, and controlling adverse psychosocial factors at work. The task appears to be more complex because of the limited quantitative parameters involved in measuring psychosocial stress, the predominance of subjective elements, and the wide variations in environmental and host factors - not only from one man/environment unit to another, but also within the same unit. from time to time. It is nevertheless necessary to research and, if possible, to achieve innovative ways and means for accomplishing this goal.

2. The application of ergonomics as an integral part of occupational health is essential. This procedure may involve a gradual shift in emphasis in the field of occupational hygiene away from its present emphasis on physical and chemical evaluations of specific hazards, which may be present less and less with improved technology in workplace design and control.

3. Much more emphasis than at present should be given to workers' participation and complete involvement in occupational health care programs. Occupational health officers should pay special attention to understanding workers' habits and life-styles. Care must be taken to observe the influence of such habits as smoking and drinking on workers' mental and physical health. A food intake and physical fitness program in the workplace can play a role in lowering the probability of hypertension and ischemic heart disease.

4. In developing countries occupational health should become a comprehensive health care program dealing with workers' nutrition and the control and treatment of parasitic diseases, in addition to the classical measures used to reduce occupational diseases and injuries.

\section{New dimensions of occupational health at the government level}

At the government level the scope of governmental responsibilities for workers' health goes beyond legislation and the inspection of workplaces. While in the area of occupational injury prevention much has to be undertaken for a long time to come in terms of government responsibility to reduce the heavy losses encountered, occupational diseases are generally on the decline in industrialized countries, not as much because of successes in the inspection of workplaces as because of the modernization of manufacturing processes. The problem of specific "occupational diseases" in developing countries, although more considerable than in industrialized countries, does not constitute the kind of serious problem as other health problems, including communicable diseases and, to some extent, work-related diseases. Consequently, the role of government, delegated to it by society, has to account for comprehensive health care aiming at the protection and promotion of its productive population, the workers.

Role in health care and legislation. Employers may debate the relationship between diseases of multiple etiology and the conditions of work. They have clas- 
sically recognized their responsibility in respect to controlling occupational health hazards. However, in view of the possible implications in workmen's compensation and the costs involved in controlling workrelated diseases, employers may doubt the legitimacy of work-relatedness and the need to provide general health care for controlling such diseases as hypertension and cardiovascular diseases, which have traditionally been the responsibility of the general health services. The role of the government, however, in citing examples of governmental health care units which cover such measures as those described earlier under in-plant health services may help educate employers and alleviate their apprehensions. From the point of view of possible compensation payment, employers should understand that there is no precise universal definition of the quantitative degree of the work-relatedness of these diseases. Epidemiologic research may succeed in demonstrating work-relatedness in some quantitative terms of occupational groups at various risks. For workmen's compensation purposes however the problem will have to be dealt with on a case-by-case basis with the general guidance of epidemiologic results, especially since, under similar conditions of exposure, people react differently and the interindividual variation involves many unresolved factors. It may also be necessary to undertake studies of the cost effectiveness of comprehensive occupational health schemes. In Botswana and the Sudan, health units of the rural and suburban governments care for workers' health in a comprehensive manner. They supervise the work environment, educate employers on better health management, educate workers on better health and safety practices, and extend primary health care to workers in the served sectors, particularly in smallscale industries and agriculture.

In many countries, there are government enterprises, eg, railroad systems and other nationalized establishments. Health care services in such instances are governmental and could be used as modern examples of broader occupational health care aiming at the total health protection and promotion of workers.

Role in training. Training in occupational health should also become oriented towards the new goal of recognition and control of work-related diseases. This shift would involve more emphasis on epidemiology, training in clinical medicine, including early diagnostic methods, and more training in the fields of psychosocial factors, ergonomics, and health education.

Role in research. Research institutions and universities have a very important role to play. Some of the problems that have to be studied are: (i) the substantiation of the degree of work-relatedness of various diseases through careful environmental and human observations and well-planned epidemiologic studies; (ii) the development and improvement of qualitative and quantitative measures for the evaluation of occupational psychosocial factors, their health and behavioral effects, and their monitoring; (iii) the improvement and facilitation of the use of ergonomics in the work environment and in areas such as agriculture and forestry, mining, semi-mechanical work, and work with the hand-operated tools commonly used in developing countries; (iv) the study of the possible role of immune responses to multiple lowlevel exposures at work, which at present may be manifest in the form of vague symptomatology; (v) the clarification of the relatedness of mutagenicity, occupational cancer, and other delayed effects to work and to factors outside work, particularly with respect to reproductive functions; (vi) the development of means of control (by measures taken within the environment) of work, workers' selection, job analysis for work demands, periodic health examination to minimize the impact of work on behavioral problems, eg, alcoholism, drug abuse, and smoking; (vii) the coordination of efforts among various health, social, and educational disciplines, including medical practitioners and occupational health specialists, to combat work-related diseases in a concerted effort within and outside the workplace (particularly influencing life-style and disseminating the need for the improvement of the work environment; and (viii) the study of the positive aspects offered by work in promoting physical and mental health when the health risks are under control and the ergonomic and psychosocial environment is satisfactory.

\section{A new program of the World Health Organization}

The specific aims of the WHO program on workrelated diseases are: (i) to identify and review the occurrence of work-related diseases in different parts of the world and to stimulate field studies of these diseases and produce a series of guidelines on control measures, (ii) to develop educational materials in ergonomics and occupational psychosocial factors, (iii) and to organize training programs in this field and introduce elements of work-related diseases in occupational health curricula. The approaches include the collation of data on the occurrence of work-related diseases in various countries by WHO collaborating centers, the preparation of study protocols of selected priorities for field studies in different countries, the conduction of studies by collaborating countries with WHO's participation, the organization of meetings of investigators to coordinate research activities and review methods, harmonize technology, and analyze results, the exchange of visits among collaborating centers to help the developing countries in research, the review of individual diseases by various task groups and the development 
of guides on control measures, the preparation of educational material on epidemiology and the organization of training courses, and the publication of a series of guides on the occurrence and control of priority work-related health problems.

A good deal of emphasis should be placed on influencing government policies towards occupational health in its new role and on the education of occupational health practitioners and employers. Training in occupational, multifactorial disease epidemiology and the organization of an internationally wellcoordinated program in this field is essential.

\section{References}

1. Cobb S, Rose RM. Hypertension, peptic ulcer and diabetes in air traffic controllers. J Am Med Assoc 224 (1973) 489-492.

2. Cheli R, Giancameria G, Canciani G. Sonda gastroduodenal per prelievo contemporaneo. Minerva Gastroenterol 20 (1974): 1, 31-35.

3. Derriennic F, Ducimetière $\mathbf{P}$, Kritsikis $\mathrm{S}$. La mortalité cardiac des Francais d'age moyen selon leur catégorie socio-professionelle et leur région de domicile. Rev Epidémiol St Public 25 (1977): 2, 131-146.

4. El Batawi MA. Health problems of industrial workers in Egypt. Ind Med 4 (1972): 2, 18-23.

5. El Batawi MA. Work-related diseases, world health magazine. Man His Environ June (1978) 10-13.

6. El Batawi MA, Noweir MH. Health problems resulting from prolonged exposure to air pollution in diesel bus garages. J Ind Health 4 (1966) $1-9$.
7. Hitz D. Drunken sailors and others, drinking problems in specific occupations. Q J Stud Alcohol 34 (1973) $496-505$.

8. Jedrychowski W. A consideration of risk factors and development of chronic bronchitis in a five-year follow-up study of an industrial population. J Epidemiol Community Health 33 (1979) 210-214.

9. Kittel F, Kornikzer M, Dramaik M. Coronary heart disease and job stress in two cohorts of bank clerks. Psychother Psychosom 34 (1980) 110-123.

10. Marmot MG, Rose G, Shipley M, Hamilton PJ. Employment grades and coronary heart disease in British Civil Servants. J Epidemiol Community Health 32 (1978) 244-249.

11. Michaelsson B, Stjernberg N, Wiman L-G. The prevalence of bronchial asthma and chronic bronchitis in an industrialized community in northern Sweden. Scand J Soc Med 10 (1982) 11-16.

12. National Institute for Occupational Safety and Health. Leading work-related diseases and injuries - United States. Morb Mortal Wkly Rep 32 (1983): 2, 24-26.

13. Sauli H. Occupational mortality in $1971-75$. Central Statistical Office of Finland, Helsinki 1979. (Study no 054).

14. Selye H. Stress in health and disease. Butterworth, London 1976.

15. Theorell T, Floderus-Myrhed B. Workload and risk of myocardial infarction: A prospective psychosocial analysis. Int J Epidemiol 6 (1977) 17-21.

16. Trice HM. Drug use and abuse in industry. Office of Drug Abuse Policy, Washington, DC 1979.

17. WHO Expert Committee. Identification and control of work-related diseases. World Health Organization, Geneva (in press).

18. World Health Organization. Occupational health programmes: Report to the 29th World Health Assembly. Geneva 1976. (Document A29/10). 